\title{
Acute Hepatorenal Failure in a Patient Following Consumption of Mushrooms: A Case Report
}

\author{
Farzad Rahmani $^{1, *}$; Hanieh Ebrahimi Bakhtavar ${ }^{2}$; Atefeh Ghavidel ${ }^{2}$ \\ ${ }^{1}$ Road Traffic Injury Research Center, Tabriz University of Medical Sciences, Tabriz, IR Iran \\ ${ }^{2}$ Department of Emergency Medicine, Tabriz University of Medical Sciences, Tabriz, IR Iran \\ *Corresponding Author: Farzad Rahmani, Department of Emergency Medicine, Tabriz University of Medical Sciences, Tabriz, IR Iran. Tel: +98-4113352078, Fax: +98-4113352078, E-mail: \\ rahmanif@tbzmed.ac.ir
}

Received: February 1, 2014; Revised: September 12, 2014; Accepted: December 15, 2014

\begin{abstract}
Introduction: One of the highly toxic mushrooms that are common in the northwest region of Iran is Amanita phalloides, which might result in renal or liver failure.

Case Presentation:This is a case report of a patient referred a few days after consumption of wild mushrooms to emergency department having gastrointestinal complaint whose experiments indicated liver and renal failure. The supportive treatment was given to the patient prescribing N-acetyl cysteine (NAC) and Livergol (silymarin) along with hemodialysis. A few days after admission to the hospital, the patient died due to severe clinical symptoms.

Conclusions: The patient was poisoned by A. phalloides complaining gastrointestinal symptoms including nausea; vomiting and watery diarrhea about six hours after consumption and then, amatoxin in the mushroom caused damage to hepatocytes and renal cells and finally led to hepatorenal failure. Deaths caused by this type of mushroom are extremely high and necessary trainings should be provided to the people by the health system not to consume wild mushrooms, especially in spring and summer.
\end{abstract}

Keywords: Mushroom Poisoning; Liver Failure; Renal Insufficiency

\section{Introduction}

Poisoning caused by the consumption of mushrooms is common and more than half of such poisonings occur following accidental consumption of the mushrooms. The best way to avoid poisoning is not to eat wild mushrooms (1). The poisonous mushrooms are divided into nine groups based on the type of toxin and the spectrum of the resulted clinical symptoms. The most important mycotoxins include protoplasmic toxins (causing cell damages and organ failures), neurotoxins (as a factor causing neurological symptoms such as loss of consciousness, coma, hallucinations, delusions and other disorders), gastrointestinal tract stimulators (leading to nausea, vomiting and abdominal symptoms) (2). The most poisonous toxin is produced by the Amanita phalloides (Figure 1) that even taking one of it can lead to death. More than $90 \%$ of deaths due to consuming mushrooms are caused by amatoxin species (2). The A. phalloides poisoning in the northern hemisphere is more prevalent in the interface between the Central Europe to the Middle East (1). Clinical manifestations of the toxicity caused by this mushroom depend on its toxins including cyclopeptide, phalloidin and alphaamanitin. The phalloidin leads to membrane dysfunction and impaired absorption in the gastrointestinal tract (3). The greatest effect of alpha-amanitin is on high-turnover cells such as the cells of gastrointestinal tract, hepatocytes and epithelium of renal tubules (1). Outcomes of mushroom poisoning are dependent on the type of mushroom eaten, early diagnosis and proper treatment (4). It is a case report of a patient having gastrointestinal symptoms with no recovery after consumption of wild mushrooms and requiring hemodialysis due to acute renal failure that died a few days after hospitalization due to severe symptoms.

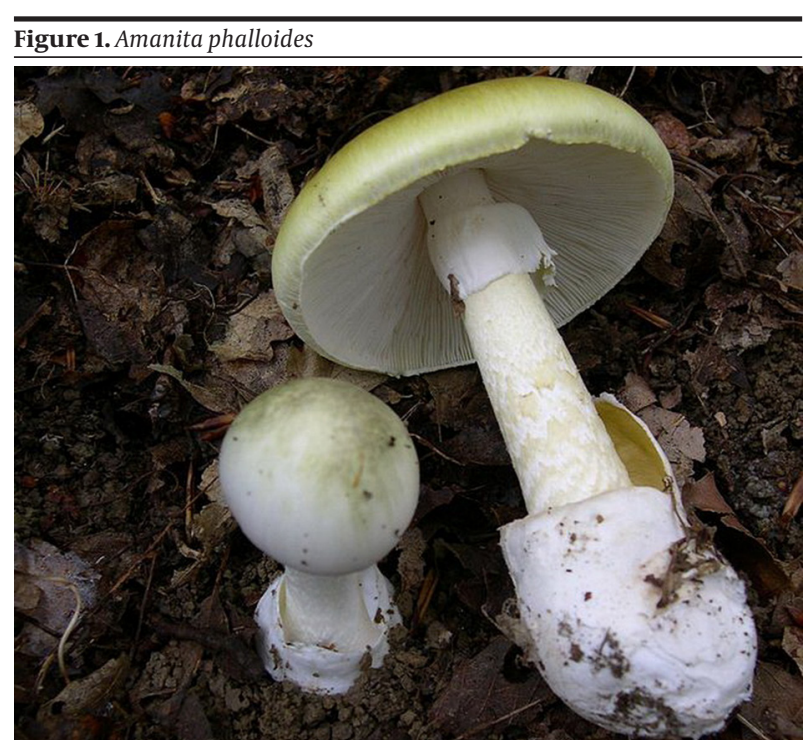

Image source: wikipedia.org

Copyright (C) 2015, Iranian Red Crescent Medical Journal. This is an open-access article distributed under the terms of the Creative Commons Attribution-NonCommercial 4.0 International License (http://creativecommons.org/licenses/by-nc/4.0/) which permits copy and redistribute the material just in noncommercial usages, provided the original work is properly cited. 


\section{Case Presentation}

The reported case was a 62-year-old man referred from a clinic to emergency department (ED) of Imam Reza Medical Research and Training Hospital, Tabriz, East Azerbaijan, Iran, at September 2013, due to refractory nausea and vomiting, which started a few days ago about 4 - 5 hours after eating 2 mushrooms with sweet smell that have been grown in his garden. The patient had non bloody vomiting and watery diarrhea. He received outpatient treatments for a few days with no recovery and finally, he was referred to ED due to disease resistance and the abdominal pain added to his symptoms. The patient's vital signs when referring to the ED were as follows: Blood pressure: $125 / 80$, Pulse Rate: $81 /$ minute, Respiratory Rate: 14/minute, Body Temperature: $36.8^{\circ} \mathrm{C}, \mathrm{O}_{2}$ saturation: $98 \%$ (in room air).

The patient appeared ill. He complained of abdominal pain, nausea and vomiting. Lung and heart examination showed no pathological findings. He had just epigastric tenderness in abdominal examination. Some tests were performed on the patient, the results of which are shown in the Table 1. Considering the clinical symptoms and the test results, the patient received emergent hemodialysis and was accordingly admitted to the hospital ICU diagnosed with the possibility of mushroom poisoning. For the delay in referring to the hospital and the occurrence of acute renal failure, the patient received merely supportive treatments along with prescribed NAC, Livergol (Silymarin) and hemodialysis; no other treatments including penicillin prescription was performed. Due to coagulopathy and increased International Normalized Ratio (INR), fresh frozen plasma (FFP) was administered to the patients during hospitalization. Meanwhile, the patient was undergoing hemodialysis after four days. The latest tests of the patient are shown in the Table 2. The patient had cardiopulmonary arrest about six days after admission following a tonic-clonic seizure and finally, he died due to fulminant hepatitis.

\section{Discussion}

Amanita phalloides from amanita mushroom species is also called as green death cap for its strong lethal property (5-7). Consumption of 20 - 50 grams of this mushroom is as lethal as $0.1 \mathrm{mg} / \mathrm{kg}$ of amatoxin poison (8). The rate of mortality caused by A.phalloides poisoning is $10-20 \%$ (9), but in the absence of liver transplantation is $83 \%$ (8). The mushroom cap is $6-15 \mathrm{~cm}$ and its color is variable from olive green to brown-green or yellow-brown becoming dark yellow at the presence of sunlight. It has no certain smell in early stages of growth, but later it will have shortly Amanita smithiana will cause renal failure the floral honeyed aroma (which is not quite pleasant) that is changed quickly to the smell of rotting potato (10). Amanita mushrooms can be recognized by a ring in their stem base called volva (11). The clinical symptoms caused by $A$ phalloides consist of four stages. The first stage is the incu- bation phase, which occurs approximately 6 -12 hours after consumption of mushrooms. At the second stage, gastrointestinal symptoms including colic abdominal pain,

\begin{tabular}{|c|c|c|}
\hline Element & Result & Normal Range \\
\hline WBC, $\times 10^{9} / \mathrm{L}$ & 13.5 & $4-10$ \\
\hline $\mathbf{H b}, \mathbf{g} / \mathbf{L}$ & 16.9 & $12-16$ \\
\hline Hct, \% & 58.3 & $36-46$ \\
\hline Plt, $\times 10^{9} / \mathrm{L}$ & 325 & $140-440$ \\
\hline FBS, $\mathrm{mmol} / \mathrm{L}$ & 131 & $70-115$ \\
\hline Urea, mmol/L & 94 & $15-40$ \\
\hline $\mathrm{Cr}, \mu \mathrm{mol} / \mathrm{L}$ & 5.6 & $0.7-1.4$ \\
\hline $\mathrm{Na}, \mathrm{mmol} / \mathrm{L}$ & 140 & $136-145$ \\
\hline $\mathbf{K}, \mathbf{m m o l} / \mathbf{L}$ & 5.6 & $3.6-5$ \\
\hline ALT, $\mu \mathrm{kat} / \mathrm{L}$ & 457 & $5-60$ \\
\hline AST, $\mu$ kat $/ \mathrm{L}$ & 485 & $5-40$ \\
\hline Alk.P, $\mu$ kat/L & 128 & $64-306$ \\
\hline Bilirubin, $\mu \mathrm{mol} / \mathrm{L}$ & 2.07 & $0.1-1.4$ \\
\hline PT, $s$ & 16.3 & $11-14$ \\
\hline INR & 1.6 & $0.9-1$ \\
\hline pH & 7.12 & $7.35-7.45$ \\
\hline $\mathrm{HCO}_{3}, \mathrm{mmol} / \mathrm{L}$ & 15 & $24 \pm 2$ \\
\hline $\mathrm{P}_{\mathrm{a}} \mathrm{CO}_{2}, \mathrm{~mm} \mathrm{Hg}$ & 41.2 & $40 \pm 4$ \\
\hline \multicolumn{3}{|c|}{$\begin{array}{l}\text { a Abbreviations: WBC, White Blood Cell; Hb, Hemoglobin; Hc } \\
\text { Hematocrit; Plt, Platelet; FBS, Fasting Blood Sugar; Cr, Creatinine } \\
\text { Na, Sodium; K: Potassium; ALT, Alanine transaminase; AST, Aspartat } \\
\text { Aminotransferase; Alk.P, Alkaline Phosphatase; PT, Prothrombin Time } \\
\text { INR, International Normalized Ratio. }\end{array}$} \\
\hline
\end{tabular}

\begin{tabular}{|c|c|c|}
\hline Element & Result & Normal Range \\
\hline $\mathrm{Hb}, \mathrm{g} / \mathrm{L}$ & 7 & $12-16$ \\
\hline Hct, \% & 25 & $36-46$ \\
\hline Urea, mmol/L & 98 & $15-40$ \\
\hline $\mathrm{Cr}, \mu \mathrm{mol} / \mathrm{L}$ & 8 & $0.7-1.4$ \\
\hline $\mathrm{Na}, \mathrm{mmol} / \mathrm{L}$ & 142 & $136-145$ \\
\hline $\mathrm{K}, \mathrm{mmol} / \mathrm{L}$ & 3.7 & $3.6-5$ \\
\hline ALT, $\mu$ kat $/ \mathrm{L}$ & 3738 & $5-60$ \\
\hline AST, $\mu$ kat/L & 2028 & $5-40$ \\
\hline Alk.P, $\mu$ kat/L & 341 & $64-306$ \\
\hline Bilirubin, mmol/L & 11.6 & $0.1-1.4$ \\
\hline PT, $s$ & 26 & $11-14$ \\
\hline PTT, $s$ & 38 & $30-40$ \\
\hline INR & 4 & $0.9-1$ \\
\hline
\end{tabular}


nausea, vomiting and watery diarrhea appeared lasting for 12 - 24 hours. The liver damage symptoms including increased level of liver enzymes and coagulopathy occur at the third stage. At the fourth stage, about 2 - 4 days after eating the mushroom, liver enzymes level will considerably increase and the patient will suffer from renal failure at the same time. Accordingly, hyperbilirubinemia, coagulopathy, hypoglycemia, hepatic encephalopathy, hepatorenal syndrome, respiratory failure and finally death happen $(1,2,8,9,12)$. The A. phalloides poisoning is diagnosed through clinically suspected mushroom poisoning and considering the patient's clinical symptoms (2, 13). Without hepatic involvement, while liver failure is developed at the early stages of the A. phalloides poisoning. The symptoms of A. phalloides poisoning appear after six hours of eating the mushroom; however, the symptoms of A. smithiana poisoning arise prior to six hours of eating the mushroom (14). The poisoning occurred by the mushrooms of Cortinarius family will cause renal failure several days or weeks after eating the mushroom (15). The gastrointestinal symptoms of Cortinarius mushrooms began to appear averagely 12 hours to 14 days after consumption (16). Amanita bisporigera is a species of Amanita mushrooms, which may develop the same clinical symptoms as A. phalloides poisoning due to having amatoxins. However, according to the statistics reported by North American Mycological Association, the poisonings by this mushroom is rare and four cases of deaths have been reported during the last 30 years as caused by such mushroom (11). Initial treatment includes volume resuscitation of the patient, correction of hypoglycemia and electrolyte abnormalities (3). Decontamination of such patients is done by gastric and duodenal lavage. Charcoal with a dosage of $0.5-1 \mathrm{~g} /$ $\mathrm{kg}$ was given every 2 - 4 hours to the patient. Penicillin G, silymarin, dialysis and liver transplantation are prescribed as treatment to such patients (9). The penicillin $G$ affects by separating the alpha-amanitin from albumin, preventing the alpha-amanitin to bind RNA polymerase, sticking to circulating amatoxins and blocking the absorption from liver cells. The silymarin exerts its effect by inhibiting the entrance of alphaamanitin into the liver cells $(12,17)$. Other suggested treatments include potential antioxidants such as ascorbic acid, cimetidine and N-acetyl cysteine (NAC). The ascorbic acid inhibits the peroxidation of lipids and plays a protective role against liver cells. The cimetidine affects by inhibiting hepatic P450 cytochromes and finally NAC acts as a precursor of glutathione having the ability to bind and inhibit free radicals produced by amatoxins (11). Hyperbaric oxygen (HBO) therapy is also recommended in early treatment of such patients (18). It is newly recommended to use fractionated plasma separation and adsorption (Prometheus) or molecular adsorbent recirculating system (MARS) in the treatment of A. phalloides poisoning that is reported as useful in maintaining the amatoxins and decreasing the need to liver transplant $(19,20)$. In this case, having no access to the mushrooms, we began to suspect of poisoning by such mushroom, based on the clinical symptoms and laboratory abnormalities (liver and renal failures) and according to previous reports indicating the prevalence of A. phalloides poisoning in the northwest of Iran. We did take accordingly the remedial measures. Furthermore, since the patient had referred to the hospital about 4 days after eating the mushroom when symptoms of liver and renal failures began to appear, the supportive treatments and hemodialysis were merely given to the patient; he was even considered for liver transplantation, but eventually he died. Given the common growth of poisonous mushrooms in the Northwest Iran, necessary measures should be taken to inform the public not to consume these types of mushrooms. The physicians should also consider the poisonings that might be occurred by such mushrooms in the patients with refractory gastrointestinal symptoms and acute liver and renal failures. The patient's accurate history for his/her possible consumption of such mushrooms should also be asked.

\section{Acknowledgements}

We would like to thank all staff in the Emergency Department and Intensive Care Unit of Imam Reza and Sina Hospitals, Tabriz, Iran.

\section{Authors' Contributions}

Atefeh Ghavidel performed the clinical data collection. Farzad Rahmani and Hanieh Ebrahimi Bakhtavar performed literature review, and drafting the manuscript. All of the authors were involved in either managing the patient or writing the manuscript. All authors read and approved the final manuscript.

\section{References}

1. Brayer AF, Schneider SM, Cevik AA. Tintinalli's Emergency Medicine. In: Tintinalli JE editor. Mushroom Poisoning.. China: Mc Graw Hill; 2011. pp. 1394-8.

2. Varshochi M, Naghili B. Mushroom poisoning in northwest of Iran. Iran J Clin Infect Dis. 2007;2(4):169-75.

3. Jan MA, Siddiqui TS, Ahmed N, Ul Haq I, Khan Z. Mushroom poisoning in children: clinical presentation and outcome. $J$ Ayub Med Coll Abbottabad. 2008;20(2):99-101.

4. Pajoumand A, Shadnia S, Efricheh H, Mandegary A, HassanianMoghadam H, Abdollahi M. A retrospective study of mushroom poisoning in Iran. Hum Exp Toxicol. 2005;24(12):609-13.

5. Isolde R. Tumor Therapy with Amanita phalloides (Death Cap): Long Term Stabilization of Prostate Cancers. J Integr Oncol. 2012;1(1)

6. Letschert K, Faulstich H, Keller D, Keppler D. Molecular characterization and inhibition of amanitin uptake into human hepatocytes. Toxicol Sci. 2006;91(1):140-9.

7. Erden A, Esmeray K, Karagoz H, Karahan S, Gumuscu HH, Basak $\mathrm{M}$, et al. Acute liver failure caused by mushroom poisoning: a case report and review of the literature. Int Med Case Rep J. 2013;6:85-90.

8. Lionte C, Sorodoc L, Simionescu V. Successful treatment of an 


\section{Rahmani F et al.}

adult with Amanita phalloides-induced fulminant liver failure with molecular adsorbent recirculating system (MARS). Rom J Gastroenterol. 2005;14(3):267-71.

9. Santi L, Maggioli C, Mastroroberto M, Tufoni M, Napoli L, Caraceni P. Acute Liver Failure Caused by Amanita phalloides Poisoning. Int J Hepatol. 2012;2012:487480.

10. Duffy TJ. An Introduction to Mushrooms \& Mushroom Poisoning. In: Duffy TJ editor. Toxic Fungi of Western North America.. USA: Mykoweb;2008. pp. 9-29.

11. Nici A, Kim S. Amanita bisporigera-Induced Hepatic Failure: A Fatal Case of Mushroom Ingestion. Case Reports Hepatol. 2011;1(1):1-3.

12. Goldfrank LR. Mushrooms. In: Goldfrank LR editor. Goldfrank's Toxicologic Emergencies.. China: Mc Graw Hill; 2007. pp. 873-80.

13. Tegzes JH, Puschner B. Toxic mushrooms. Vet Clin North Am Small Anim Pract. 2002;32(2):397-407.

14. West PL, Lindgren J, Horowitz BZ. Amanita smithiana mushroom ingestion: a case of delayed renal failure and literature review. $J$ Med Toxicol. 2009;5(1):32-8.

15. Danel VC, Saviuc PF, Garon D. Main features of Cortinarius spp. poisoning: a literature review. Toxicon. 2001:39(7):1053-60.

16. Saviuc P, Danel V. New syndromes in mushroom poisoning. Toxicol Rev. 2006;25(3):199-209.

17. Pengilley AJ, Kelly PM. Amanita phalloides poisoning and treatment with silibinin in the Australian Capital Territory and New South Wales. Med JAust. 2013;199(10):659-60.

18. Floersheim GL, Weber O, Tschumi P, Ulbrich M. [Clinical deathcap (Amanita phalloides) poisoning: prognostic factors and therapeutic measures. Analysis of 205 cases]. Schweiz Med Wochenschr. 1982;112(34):1164-77.

19. Bergis D, Friedrich-Rust M, Zeuzem S, Betz C, Sarrazin C, Bojunga J. Treatment of Amanita phalloides intoxication by fractionated plasma separation and adsorption (Prometheus(R)). J Gastrointestin Liver Dis. 2012;21(2):171-6.

20. Shi Y, He J, Chen S, Zhang L, Yang X, Wang Z, et al. MARS: optimistic therapy method in fulminant hepatic failure secondary to cytotoxic mushroom poisoning--a case report. Liver. 2002;22 Suppl 2:78-80. 